\title{
Some epidemiological aspects of nosocomial infections. Antibiotic sensitivity rates of isolated bacteria from nosocomial infections - A prospective study from 2012 to 2013 in the Academic Emergency Hospital Sibiu, Romania
}

Victoria Bîrluțiu ${ }^{1,2^{*}}$, Rareş-Mircea Bîrluțiu ${ }^{1}$

From The 10th Edition of the Scientific Days of the National Institute for Infectious Diseases "Prof Dr Matei Bals"

Bucharest, Romania. 15-17 October 2014

\section{Background}

The aim of this study was to monitor the nosocomial infections in our hospital (The Academic Emergency Hospital in Sibiu), to monitor the antibiotic sensitivity patterns of isolated bacteria from nosocomial infections and to follow the variation in resistance from 2012 to 2013, in order to establish the first-line therapy for critical patients with nosocomial infections.

\section{Methods}

We collected the data related to hospital service units where nosocomial infections had been identified, the etiologic agents that were identified, the site of infection and the antibiotic sensitivity rates of nosocomial infections.

\section{Results}

The total number of isolated strains was 413, 231 in 2012 and 182 in 2013. In the intensive care units 151 nosocomial infections were identified; 88 strains in the Surgical Department, 27 strains in the Department of Gynecology and Obstetrics, 24 strains in the Department of Neurosurgery and 23 in the Orthopedic Department. 19 strains were identified in the Neurology Department and also in the Internal Medicine Department, 17 strains were identified in the Urology Department, 14 in the Aesthetic Surgery Department, 8 in the Nephrology Department, 8 in the

\footnotetext{
* Correspondence: victoriabirlutiu@yahoo.com

1"Lucian Blaga" University Sibiu, Faculty of Medicine Sibiu, Romania

Full list of author information is available at the end of the article
}

Hematology Department and 5 in the Gastroenterology Department. 3 strains were isolated in each of the following departments: Diabetes and Nutrition Diseases, E.N.T and Neonatology and 1 strain was identified in the Cardiology Department. In terms of etiology, the most commonly isolated were: Enterobacter spp. (111) followed by Acinetobacter spp. (71), Escherichia coli (59), Staphylococcus aureus (46), Klebsiella spp. (30), Enterococcus spp. (20), Pseudomonas spp. (19), Proteus spp. (19), fungi (17), coagulase-negative Staphylococcus (11), Burkholderia cepacia (8), Serratia marcescens (5).

\section{Conclusion}

Most cases of nosocomial infections were reported from ICUs and surgery, representing surgical wound infections and nosocomial pneumonia. In aspiration pneumonia patients, Acinetobacter spp. (22) was isolated the most frequently. In blood cultures the most frequently isolated strains were Klebsiella pneumoniae and Staphylococcus aureus. Burkholderia cepacia was associated with hematologic malignancies. Enterobacter spp. was the most common etiologic agent isolated from surgical wound infections and from nosocomial urinary tract infections. The use of broad-spectrum antibiotics was associated with the emergence of carbapenemase in over 90\% of the isolated strains of Acinetobacter spp. and Enterobacter AmpC (+), in 54.05\% of Enterobacter extendedspectrum beta-lactamase (ESBL + ), in $20.34 \%$ of the Escherichia coli ESBL+ isolated strains. Methicillin- 
resistant Staphylococcus aureus (MRSA) was isolated in $67.74 \%$ of all Staphylococcus aureus strains.

\section{Authors' details}

1"Lucian Blaga" University Sibiu, Faculty of Medicine Sibiu, Romania.

${ }^{2}$ Academic Emergency Hospital Sibiu, Romania.

Published: 15 October 2014

doi:10.1186/1471-2334-14-S7-O29

Cite this article as: Bîrluțiu and Bîrluțiu: Some epidemiological aspects of nosocomial infections. Antibiotic sensitivity rates of isolated bacteria

from nosocomial infections - A prospective study from 2012 to 2013 in

the Academic Emergency Hospital Sibiu, Romania. BMC Infectious

Diseases 2014 14(Suppl 7):O29.

Submit your next manuscript to BioMed Central and take full advantage of:

- Convenient online submission

- Thorough peer review

- No space constraints or color figure charges

- Immediate publication on acceptance

- Inclusion in PubMed, CAS, Scopus and Google Scholar

- Research which is freely available for redistribution

Submit your manuscript at www.biomedcentral.com/submit 